\title{
Aggressive case of postpubertal cherubism: A case report
}

\author{
Ghadah Aljumah $^{1}$, Ahmed Nasser ${ }^{*}$, Ahmed Alomar ${ }^{2}$, Faleh alshahrani ${ }^{3}$ and Talal Bokhamseen ${ }^{4}$ \\ ${ }^{1}$ Bachelor of dental surgery, Oral and Maxillofacial department, King Abdulaziz Medical City, Ministry of National Guard Health Affairs, Riyadh, Saudi Arabia \\ ${ }^{2}$ Assistant consultant, Oral and Maxillofacial department, King Khalid university Hospital, King Saud University Medical City, Riyadh, Saudi Arabia \\ ${ }^{3}$ Senior Oral and Maxillofacial resident, Oral and Maxillofacial department, King Fahad Medical City, Ministry of Health, Riyadh, Saudi Arabia \\ ${ }^{4}$ Oral and Maxillofacial consultant, Oral and Maxillofacial department, King Abdulaziz Medical City, Ministry of National Guard Health Affairs, Riyadh, Saudi Arabia
}

\begin{abstract}
Cherubism is a non-neoplastic fibro-osseous lesion that is diagnosed among children based on its characterization by bilateral painless enlargement of jaws that offers a cherubic appearance to the affected persons. Cherubism treatment is combative given that it is believed that the lesion regress at puberty but cases with severe facial disfiguration can be corrected surgically. This case reports a 23-year-old male reported to the Department of Oral and Maxillofacial surgery at National Guard Health Affairs, King Abdulaziz Medical City, Riyadh, Saudi Arabia by his mother with chief complaint of asymptomatic, progressive and bilateral enlargement of the mandible. Based on facts and the clinical, historical, family and radio-graphical findings this report prepared a cherubism diagnosis of the patient. The purpose of this case report is to present the unusual postpubertal cherubism.
\end{abstract}

\section{Introduction}

Cherubism is a benign of an autosomal dominant inherited fibroosseous bone disease. William a. Jones 1933, a Canadian radiologist described the condition first as familial multilocular cystic disease of the jaws in three Jewish siblings [1]. The upward gaze or 'eyes to heaven' results from lower lid retraction in relation to the diffuse enlargement of the lower half of the face or to an upward displacement of the eye from a mass involving the orbital floor [2]. The lesion is characterized by frequently symmetrical enlargement of the maxilla and mandible as a result of the replacement of normal bone by proliferation of fibrovascular tissue containing multinucleated giant cells [3]. Usually The first signs of the disease appear between 1 and 3 years of age [4]. Motamedi [5] proposed a grading system for cherubism in 1998 which was modified by Raposo-Amaral et al. [6] in 2007 (Table1). The authors in this article are reporting a case of a 23 -year-old male patient with bilateral swelling of the lower jaw which was diagnosed with cherubism grade I class 5 .

\section{Case report}

A 23-year-old male reported to the Department of Oral and Maxillofacial surgery at National Guard Health Affairs, King Abdulaziz Medical City, Riyadh, Saudi Arabia by his mother with chief complaint of asymptomatic, progressive and bilateral enlargement of the mandible. The history revealed that the patient had been born as a full term normal delivery to a healthy 46 years old mother with a low birth weight $1.2 \mathrm{~kg}$ thorough he was admitted to natal intensive care unit and discharged after two weeks in good condition. The patient showed no abnormalities until the age of 2, his mother noticed a symmetrical bilateral enlargement of the lower face. This enlargement had continued progressive fashion as the patient grows. Family history showed that his brother had a similar fullness of the cheeks and passed away at the age of 13 without underlying diagnosis. On physical examination, it was seen that patient has mild intellectual disabilities (IDs). No abnormality was found on clinical examination of the chest. cardiovascular examination revealed a positive nails clubbing, and by auscultation the first and second heart sounds were normal with no audible murmur. No cutaneous pigmentation or other congenital abnormality was present; there was no evidence of endocrinal disturbance. On extraoral examination normal color of the face was seen, Frontal bossing with normal hair line, normal eyebrows, no epicanthic fold, no hypertelorism and there was no ophthalmic abnormality. Normal nasal bridge, bilateral asymmetrical enlargement of the mandible. The enlargement was nontender and hard on palpation. On intraoral evaluation revealed multiple missing teeth in both maxillary and mandibular arch as the mother gave a history of teeth exfoliation in the last ten years.

\section{Radiographic findings}

Panoramic radiograph was taken and revealed an expansile, multilocular radiolucencies with soap-bubble appearance distributed in the mandible involving the ramus and body of the mandible extending up to parasymphyseal and symphseal region as there is an extensive loss and impaction of multiple teeth (Figure 1). Patient was referred for plain CT scan of facial bones and 3D images were also reconstructed in color rendered mode (Figure 2) which revealed multiple expansile multilocular radiolucencies in anterior 2/3rd ramus, extending up to parasymphyseal and symphseal region causing buccolingual bone expansion with bilateral involvement of the coronoid process sparing condyles with evident larger swelling of the right side (Figure 3).

Correspondence to: Ahmed Essam Nasser, Bachelor of dental surgery, Oral and Maxillofacial department, King Abdulaziz Medical City, Ministry of National Guard Health Affairs, Riyadh, Saudi Arabia, Tel: +966501314141;

Key words: cherubism, fibro-osseous, autosomal dominant, postpubertal

Received: January 17, 2018; Accepted: January 24, 2018; Published: January 27, 2018 
Table 1. Cherubism grading system according to Motamedi and Raposo-Amaral.

\begin{tabular}{|l|l|}
\hline $\begin{array}{l}\text { Grade I: } \\
\text { Lesions of the mandible without signs of root resorption }\end{array}$ & $\begin{array}{l}\text { Class 1 solitary lesion of the mandibular body } \\
\text { Class 2 multiple lesions of the mandibular body } \\
\text { Class 3 solitary lesion of the ramus } \\
\text { Class 4 multiple lesions of the rami } \\
\text { Class 5 lesions involving the mandibular body and rami }\end{array}$ \\
\hline $\begin{array}{l}\text { Grade II: } \\
\text { Lesions involving the mandible and maxilla without signs of root resorption }\end{array}$ & $\begin{array}{l}\text { Class 1 lesions involving the mandible and maxillary tuberosities } \\
\text { Class 2 lesions Involving the mandible and anterior maxilla } \\
\text { Class 3 lesions involving the mandible and entire maxilla }\end{array}$ \\
\hline $\begin{array}{l}\text { Grade III: } \\
\text { Aggressive lesions of the mandible with signs of root resorption }\end{array}$ & $\begin{array}{l}\text { Class 1 solitary lesion of the mandibular body } \\
\text { Class 2 multiple lesions of the mandibular body } \\
\text { Class 3 solitary lesion of the ramus } \\
\text { Class 4 multiple lesions of the mandibular rami } \\
\text { Class 5 lesions involving the mandibular body and rami }\end{array}$ \\
\hline $\begin{array}{l}\text { Grade IV: } \\
\text { Lesions involving the mandible and maxilla and showing signs of root resorption }\end{array}$ & $\begin{array}{l}\text { Class 1 lesions involving the mandible and maxillary tuberosity } \\
\text { Class 2 Lesions involving the mandible and anterior maxilla } \\
\text { Class 3 lesions involving the mandible and entire maxilla }\end{array}$ \\
\hline $\begin{array}{l}\text { Grade V: } \\
\text { The rare, massively growing, aggressive, and extensively deforming juvenile cases involving }\end{array}$ \\
$\begin{array}{l}\text { Grade VI: } \\
\text { The rare, massively growing, aggressive, and extensively deforming juvenile lesions involving the maxilla, mandible and orbits }\end{array}$ \\
\hline
\end{tabular}

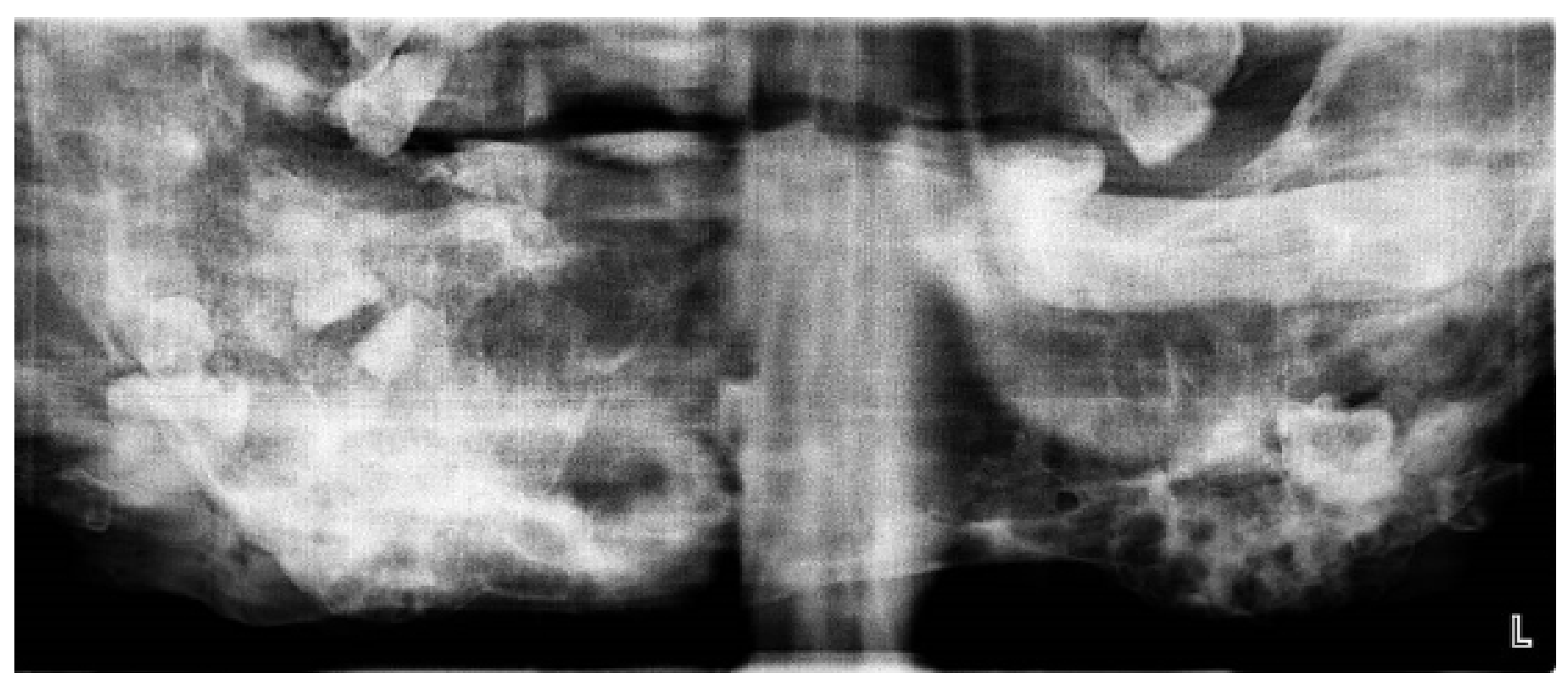

Figure 1. Panoramic radiograph showing bilateral multilocular radiolucencies areas.

\section{Laboratory investigations}

Laboratory investigations showed a hemoglobin level of $11.9 \mathrm{gm} /$ $\mathrm{dl}$ (normal 13 to $18 \mathrm{gm} / \mathrm{dl}$ ), hematocrit value of $38 \%$ (normal range between 40 to 52\%), each being slightly low, Parathyroid hormone level and other lab investigations were within normal limits.

\section{Mutation analysis}

Mutation analysis of SH3BP2 was negative, no pathogenic variant was identified in exon 9 of the SH3BP2 gene in the submitted specimen. No pathogenic variant known to be associated with cherubism was identified by this analysis of exon 9 of the SH3BP2 gene. While this gene consists of 13 exons. Almost all published pathogenic variants have been missense changes located in exon 9 and affecting four residues within a 6-amino acid motif (positions 415-420). In one study of 15 unrelated families, SH3BP2 pathogenic variants were identified in $80 \%$ of individuals with clinically diagnosed cherubism [7]. Although cherubism cannot be excluded if no mutation in SH3BP2 was found because of possible genetic heterogeneity [8].

\section{Discussion}

Cherubism is considered to be hereditary with autosomal dominant pattern with $100 \%$ penetration in males and $50-70 \%$ in females [9]. Although it belongs to the non-neoplastic bone lesions group that involves the mandible. Manpreet Kaur et al. [3] reported the disease manifest itself in childhood between the age of one to three years old. Cherubism may take various clinical forms, from clinically unapparent with a mild form of cherubism to highly aggressive [10]. premature exfoliation of primary teeth and displacement of the permanent dentition can be observed due to substitution of bone into a fibrous tissue, resulting in occlusophathologie [5]. The treatment plan for cherubic patients must be individually determined for each patient as the severity varies between the cases, RR Addante [11] reported that the extension of lesions, the potential for pathologic fracture, and the high probability of eventual regression must be considered. cherubism is expected to regress spontaneously after puberty, however postpubertal actively expanding lesions were also reported [12]. Surgical intervention is indicated to improve mastication, swallowing, phonation and 

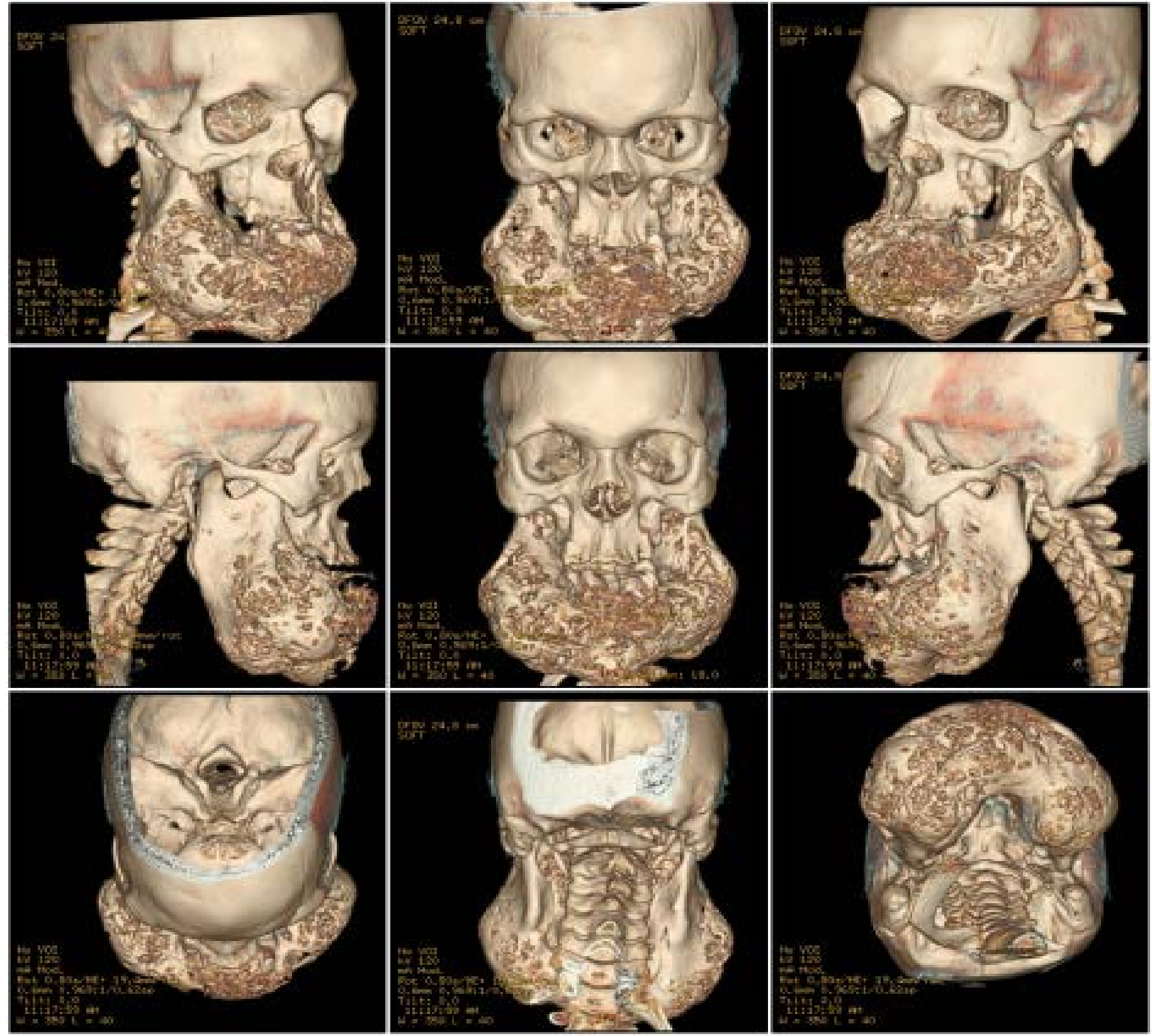

Figure 2. CT scan of facial bones reconstructed in color rendered 3D mode.

aesthetic, breathing problems are usually absent in cherubic patients, but the backward displacement of the tongue can cause an upper airway obstruction $[13,14]$. However surgical intervention during growth phase showed relapse followed by more aggressive clinical course [15]. Shah et al. [16] reported a case of cherubism in a 10 -year-old child who developed leiomyosarcoma after two surgical recontouring procedures. Curettage was the dominating procedure in reports based on larger clinical studie $[8,17]$. Cherubism is known to be a hemorrhagic lesion, Raposo-Amaral et al. [6] reported an extensive resection was performed in two stages to prevent excessive blood loss in 8 children age 6 to 15 years old with severe cherubism. Henry.F et al. [18] reported on preoperative arterial embolization as there were no unexpected bleeding during curettage and blood loss was minimized as a two stages surgical procedure is not always applicable. However,
Al-Omar et al. [19] reported a surgical intervention of postpubertal cherubism involving the mandible and maxilla in a 20 -year-old female as a single stage without preoperative arterial embolization.

\section{Conclusion}

Cherubism is an autosomal dominant disorder belongs to a group of non-neoplastic bone lesions affecting the jaws while the severity ranges from no clinically or radiologically detectable features to severe deformity. Patients parents usually seek medical attention mainly for esthetic and functional concerns. it is necessary for the dentist to be familiar with the condition for early detection.

\section{Conflicts of interest}

There are no conflicts of interest. 


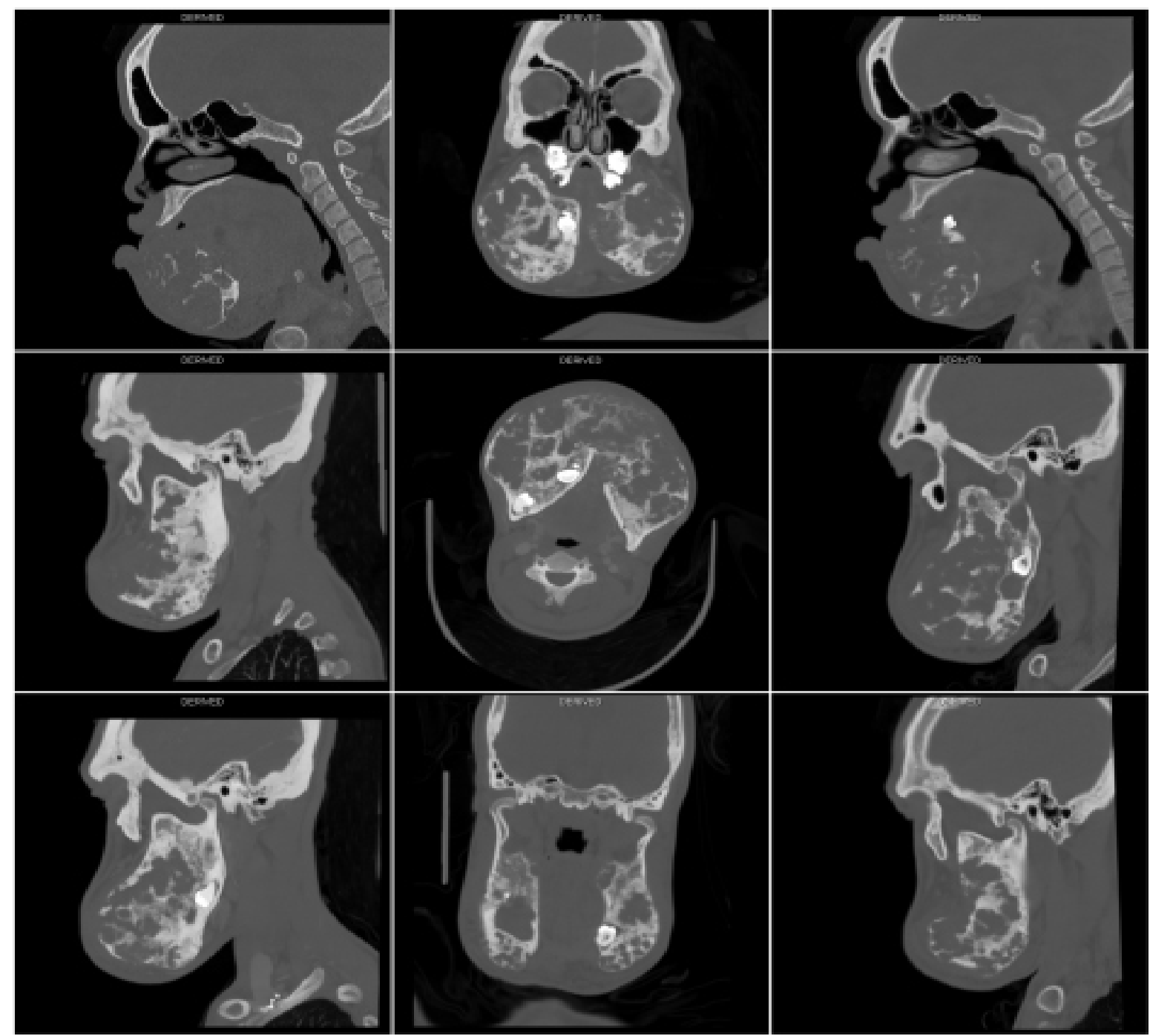

Figure 3. CT scan of facial bones in coronal, axial and sagittal sections showing severely deformed mandible.

\section{References}

1. Jones WA (1933) Familial multilocular cystic disease of the jaws. The American Journal of Cancer 17: 946-950.

2. Hawes MJ (1989) Cherubism and its orbital manifestations. Ophthal Plast Reconstr Surg 5: 133-140. [Crossref]

3. Kaur M, Shah S, Babaji P, Singh J, Nair D, et al. (2014) Cherubism: A rare case report. J Nat Sci Biol Med 5: 488-491. [Crossref]

4. Roginsky V, Ivanov A, Ovtchinnikov I, Khonsari R (2009) Familial cherubism: The experience of the Moscow Central Institute for Stomatology and Maxillo-Facial Surgery. Int J Oral Maxillofac Surg 38: 218-223. [Crossref]

5. Motamedi MHK (1998) Treatment of cherubism with locally aggressive behavior presenting in adulthood: Report of four cases and a proposed new grading system. $J$ Oral Maxillofac Surg 56: 1336-1342. [Crossref]

6. Raposo-Amaral CE, Guidi MDC, Warren SM, A Imeida AB, Amstalden EMI, et al. (2007) Two-stage surgical treatment of severe cherubism. Annals of Plastic Surgery 58: 645-651. [Crossref]

7. Habal MB (2001) Mutations in the gene encoding c-Abl-binding protein SH3BP2 cause cherubism. Journal of Craniofacial Surgery 12: 515.

8. Papadaki ME, Lietman SA, Levine MA, Olsen BR, Kaban LB, Reichenberger EJ (2012) Cherubism: best clinical practice. Orphanet Journal of Rare Diseases 7. [Crossref]
9. Cornelius EA, McClendon JL (1969) Cherubism--hereditary fibrous dysplasia of the jaws. Roentgenographic features. Am J Roentgenol Radium Ther Nucl Med 106: 136143. [Crossref]

10. Meng X, Yu S, Yu G (2005) Clinicopathologic study of 24 cases of cherubism. Int J Oral Maxillofac Surg 34: 350-356. [Crossref]

11. Addante RR, Breen GH (1996) Cherubism in a patient with Noonan's syndrome. J Oral Maxillofac Surg 54: 210-213. [Crossref]

12. Ozan B, MuÄŸlali M, Celenk P, GÃ̃/4nhan O (2010) Postpubertal nonfamilial cherubism and teeth transposition. J Craniofac Surg 21: 1575-1577. [Crossref]

13. Atalar MH, Albayrak E, Erdlinc P, Bulut S (2008) Cherubism as a rare cause of bilateral expansion of the mandible: Radiological manifestations. Journal of Hong Kong College of Radiologists 11: 76-80.

14. Lima GDMG, Almeida JD, Cabral LAG (2010) Cherubism: Clinicoradiographic Features and Treatment. Journal of Oral and Maxillofacial Research.

15. Timoşca GC, Găleşanu RM, Cotuţiu C, Grigoraş M (2000) Aggressive form of cherubism: report of a case. J Oral Maxillofac Surg 58: 336-344. [Crossref]

16. Shah N, Handa KK, Sharma MC (2004) Malignant mesenchymal tumor arising from cherubism: A case report. J Oral Maxillofac Surg 62: 744-749. [Crossref]

17. Von Wowern N (2000) Cherubism: a 36-year long-term follow-up of 2 generations in different families and review of the literature. Oral Surg Oral Med Oral Pathol Oral Radiol Endod 90: 765-772. [Crossref] 
18. Henry F, Testelin S, Gauvin AC, Poirier J, Henry E (2003) Cherubism: the value of imaging and preoperative embolization. J Radiol 84: 1774-1778. [Crossref]
19. Al-Omar AF, Moussa BG, El-Dakrory UA (2015) Cherubism. Egyptian Journal of Oral \& Maxillofacial Surgery 6: 62-65.

Copyright: $\odot 2018$ Aljumah G. This is an open-access article distributed under the terms of the Creative Commons Attribution License, which permits unrestricted use, distribution, and reproduction in any medium, provided the original author and source are credited. 